\title{
Best Bets for Accelerating Family Planning in Pakistan: Inducting men, sharing responsibility
}

Kiren Khan

Zeba Sathar

Population Council

Follow this and additional works at: https://knowledgecommons.popcouncil.org/departments_sbsr-rh

Part of the Health Services Research Commons How does access to this work benefit you? Let us know!

\section{Recommended Citation}

Khan, Kiren and Zeba Sathar. 2020. "Best Bets for Accelerating Family Planning in Pakistan: Inducting men, sharing responsibility," brief. Islamabad: Population Center Pakistan. 


\section{Best Bets for Accelerating Family Planning in Pakistan}

\section{Inducting Men, Sharing Responsibility}

The need for greater male engagement in sexual and reproductive health, including family planning, has been underscored in the 1994 International Conference on Population and Development (ICPD) and in numerous subsequent international agreements. ${ }^{1}$ However, even though policies in Pakistan do mention this involvement-for example in the 2012 FP2020 pledges, 2017 renewal of pledges, relevant recommendations of the Council of Common Interests (CCI), and some of the provincial Costed Implementation Plans (CIPs) -

\section{International Evidence for Engaging Men and Boys in Family Planning}

The need to include men and boys outweighs the argument that it will eat into investments in women's sexual and reproductive health and in fact underscores their important potential role as supportive of women's decisions and as caring parents. ${ }^{2}$

Not many governments have yet invested in prioritizing men in family planning policies ${ }^{3}$ or in scaling up effective programs ${ }^{4,5}$ probably because of the practical challenges entailed. However, international programming is evolving to recognize men's important role across the life course, not only as supporters of their partners' family planning use, but also as users themselves in their own right, and as important agents of change who can be engaged to help transform social norms the country's family planning program remains more or less exclusively aimed at women. Evidence from both international programming and within the country suggests that inducting men in family planning could improve results. Given the large youth cohort entering reproductive life in Pakistan, there are compelling grounds for also including younger men and adolescent boys, especially those about to wed, into the reproductive health and family planning strategy.

and values around fertility and family planning in their communities. ${ }^{6}$ In particular, there is a growing emphasis on including adolescent boys in sexual and reproductive health (SRH) programming since the gender perspectives, knowledge, attitudes, and skills they acquire in these years set the stage for their future health and relationships. ${ }^{7}$

The specific practices adopted to engage men and boys range from proven practices (e.g., social marketing, outreach with male motivators) and promising interventions (e.g., clinic provision of information and services, outreach through peer educators/mentors, mass media, community dialogue, and life skills-based education), to emerging interventions (e.g., social media, mHealth, hotlines, and engaging religious leaders). ${ }^{* 8}$ 


\section{Men as Supporters of Women in Family Planning}

Most pilot programs have sought to improve their attitudes towards family planning; enhance their knowledge and use of specific methods of contraception; and/or address gender norms around family planning use to enhance male support for women's effective and continuous use of family planning. A major route to enhance support are interventions which aim to improve couple communication, which is linked with increased contraceptive use.

Men generally are interested in their partners' wellbeing and want to be involved in $\mathrm{SRH}$, and programs positioning them as caring partners rather than irresponsible adversaries enjoy far more success. ${ }^{11}$ A popular approach is use of peer educators, who can successfully deliver reproductive health messages and initiate changes in household gender dynamics. ${ }^{12}$ Hotlines and social media networks such as $\mathrm{Nivi}^{13}$ also represent a promising intervention for informing men more directly and discreetly about contraceptives and available services, as well as about other SRH issues, such as sexually transmitted infections and HIV / AIDS. ${ }^{14}$

\section{Adolescents and Young Men}

There is a growing recognition that engagement about gender and health issues should begin early, during childhood and early adolescence, when boys and girls begin to solidify their identities and develop the attitudes and skills that lay the foundation for future sexual and reproductive health and well-being. Projects like GrowUp Smart show that health-seeking behaviors and communication on puberty with parents and other trusted adults can be improved among very young adolescents. Life skills-based education (LSBE) programs for young people are promising, and more effective when they challenge inequitable gender norms, provide creative experiences of equitable behavior choices, and make explicit links between sexuality and fatherhood. In the Gender Roles, Equality \& Transformations (GREAT) project, encouraging adolescent boys and young men to support their partners in family planning proved to be successful in tackling age-long gendered behaviors linked with gender-based violence and exclusion of boys and young men from SRH. ${ }^{15}$

Similar positive public health and gender equity initiatives include the Steppingstone project in South Africa, SASA in Uganda, and Program $\mathrm{H}$ in Brazil ${ }^{16}$ as well as the Prachar project which increased awareness about the benefits of family planning for health timing and spacing of pregnancies (HTSP) in Bihar, India. ${ }^{17}$ The Iranian family planning program provided family planning counseling, information, and services equally to men and women, without any discrimination, and this was a major factor in its success. ${ }^{18}$
Reviews show that integrated approaches that include both service provision and multiple communication interventions are more influential in changing men's SRH practices and awareness than single-focus interventions ${ }^{9}$; programs that include gender-transformative messages and work at multiple levels, for example, individual, household, and community, taking into account relationships, social institutions, gatekeepers, community leaders, and the like, have proved more effective in changing men's behavior and gender-related attitudes. ${ }^{10}$

\section{Men as Agents of Change}

Men's attitudes toward family planning and fertility norms can be influenced positively, particularly by providing them opportunities to talk about their experiences with other men and discuss issues with supportive and trusted influential people in their lives. ${ }^{19}$ Such interventions typically bring youth, men, and women together, sometimes with community and religious leaders, to create a unified understanding of norms, values, and roles around family planning. ${ }^{20}$

Involving influential male leaders can help legitimize men's role in family planning. In this regard, religious leaders in Bangladesh have been oriented to family planning practices, male responsibility in family planning, and other related issues. ${ }^{21}$ More innovative approaches to promoting community dialogue, such as the Village Saving Loaning Asso $\neg$ ciations in Uganda-a microfinance program focused on men, have linked messaging about family planning with the broader context of economic betterment, which would be of immediate interest to men. ${ }^{22}$ 


\section{Men as Contraceptive Users}

Social marketing, a proven high impact practice (HIP), has focused to a large extent on challenging social norms and helping to overcome barriers to acceptability of contraceptive use, while also increasing the availability of contraceptives and services in several settings. In Pakistan, this intervention has been associated with increase in condom use. ${ }^{23,24}$

Apart from making conventional reproductive health services more male-friendly, Hardee and colleagues ${ }^{25}$ recommend reaching men with information "where and when they need it," for example through volunteers who talk to men as they do agricultural work, as has been tried with success in El Salvador and Honduras, or through pharmacies and drug shops, which is a promising HIP especially in settings where health facilities focus largely on women and children and men are reluctant to seek services. Likewise, workplace health programs can be effective avenues for reaching men. ${ }^{26}$

Additionally, employing male health workers and service providers to become the link between men and the health system and information sources is a proven practice for addressing men's apparent opposition to family planning, increasing their knowledge and information, enhancing couple communication, and increasing contraceptive use. Use of male motivators and other trained male peers has repeatedly demonstrated success, albeit on a small scale. ${ }^{27}$

Vasectomy, or male sterilization, is considered a very effective male method of contraception but is not widely sought or used by men, except in the US and UK. A lack of knowledge or bias among service providers and widespread misconceptions among men and their communities about the method and its side effects contributes to men's low use of and limited access to vasectomies. However, programming experience indicates that these barriers can be overcome and use of vasectomy significantly increased. In Costa Rice, use of vasectomy was increased through communications programming linking the method to men's desire to take care of their families, while in Ghana, the ACQUIRE Project achieved success by building the capacity of physicians to provide no-scalpel vasectomy (NSV) services, training clinic staff in "male-friendly" services, and implementing an extensive outreach campaign. Similarly, in Iran, vasectomy uptake increased when misconceptions equating vasectomy to castration were removed through information campaigns. ${ }^{29}$ In Guatemala, the Women's International Network for Gua $\neg$ temalan Solutions (WINGS) increased use of vasectomy by publicizing the availability of services on Facebook. ${ }^{30}$

\section{The Case for Male Engagement as One of the Best Bets for Pakistan}

Some efforts have been made in Pakistan to induct men in family planning, but they could not be mainstreamed or sustained. For example, successive programs at the national and provincial level have provided for provision of family planning services to men at the workplace, in large registered institutions and through the sporadic use of hakims and homeopaths. However, the only concerted and largescale effort of this nature- the Continuous Motivations Scheme of the 1970s, which engaged husband-and-wife teams to motivate couples to adopt family planningeventually ceased due to political interference. ${ }^{31}$

More recently, the Family Advancement for Life and Health (FALAH) project provided evidence for multiple interventions to successfully engage men in family planning as users, supporters, and also change agents. The project demonstrated that communications programming emphasizing the benefits of HTSP resonates with men's own desire to protect the health of their wives and children. In Khyber Pakhtunkhwa and Balochistan provinces, local religious scholars and leaders were oriented and trained to have a large positive influence on attitudes towards family planning. In Sindh, interactive theater performances were effective in engaging community men and women in dialogue on family planning and increasing their utilization of clinical services, arranged on-site through Mobile Support Units. ${ }^{32}$ The project also contributed to male-friendly services by orienting male health service providers to the permissibility of family planning in Islam in 20 districts. ${ }^{33}$ However, strategies to replicate or scale up such interventions have yet to emerge.

Most women also practice family planning and choose methods in consultation with their husbands. These are all positive signs of the significant interest and readiness on the part of Pakistani men to take responsibility in family planning.

Notwithstanding the lack of sustained large-scale efforts, the use of male methods of family planning (condoms and withdrawal) has seen a phenomenal rise in the country from 3.2 in $1991^{34}$ to $17.2 \%$ in $2018^{35}$, and a majority $(73 \%)$ of men disagree with the stereotypical statement that family planning is only women's business. ${ }^{36}$ 
However, in the absence of effective proactive strategies, men continue to lack the information and services they essentially need, both as users of contraceptives, and to support their wives' use of suitable methods. In qualitative studies, men from different parts of the country have complained of finding no male provider at health facilities to discuss family planning with, especially their concerns and questions about female methods that may have side effects. ${ }^{37}$

In a study spanning eight districts of Pakistan, men identified lack of information sources as a major obstacle in using and supporting their wives' use of contraceptives. This barrier existed "across the board, even in large cities". ${ }^{38}$ Due to cultural barriers, they are often barred from exchanges on the subject between available female providers and their wives. ${ }^{39}$

Non-availability of services in the evening is also an obstacle, as it is difficult for them to take time off from work. ${ }^{40,41}$ Typically, their only direct access to family planning information and services is through pharmacies, which

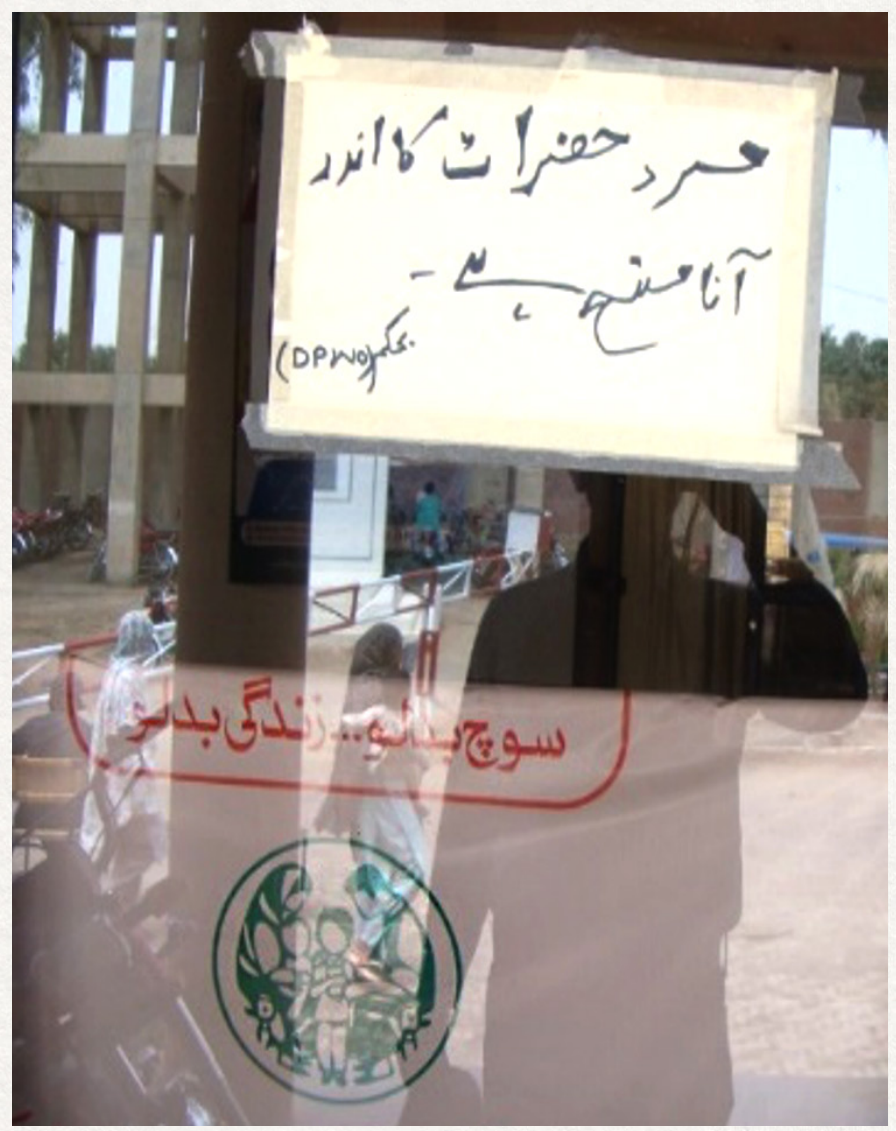

This is a list of charges for various family planning methods available at a Family Health Center. The sentence pointed out originally said, "Female and male sterilization surgery is conducted free of cost," but the words "and male" have been inked out.

Photos by Mumraiz Khan, Population Council do not provide detailed information.When asked directly, men say they want male providers with whom they can discuss sensitive issues related to their sexual and reproductive health, and who can provide relevant family planning information, counseling, and contraceptive methods to them directly. They want to help their wives make informed choices about which contraceptive method to use, based on a complete picture of advantages and disadvantages, and practical information on how to use the product or behavior safely, consistently, and effectively. They are extremely concerned about possible harmful health effects of contraceptive use by their wives, especially with the use of injectables and intrauterine devices (IUDs) ${ }^{42}$, and also perceive that service providers do not have the capacity to guide their wives in coping with side effects. ${ }^{43}$ This concern is supported by a recent assessment of public and private health facilities in Punjab province, which found that no cadre of service providers had complete and accurate knowledge about any specific contraceptive method, and a dire need for refresher training in contraceptive technology and client-centered care. ${ }^{44}$
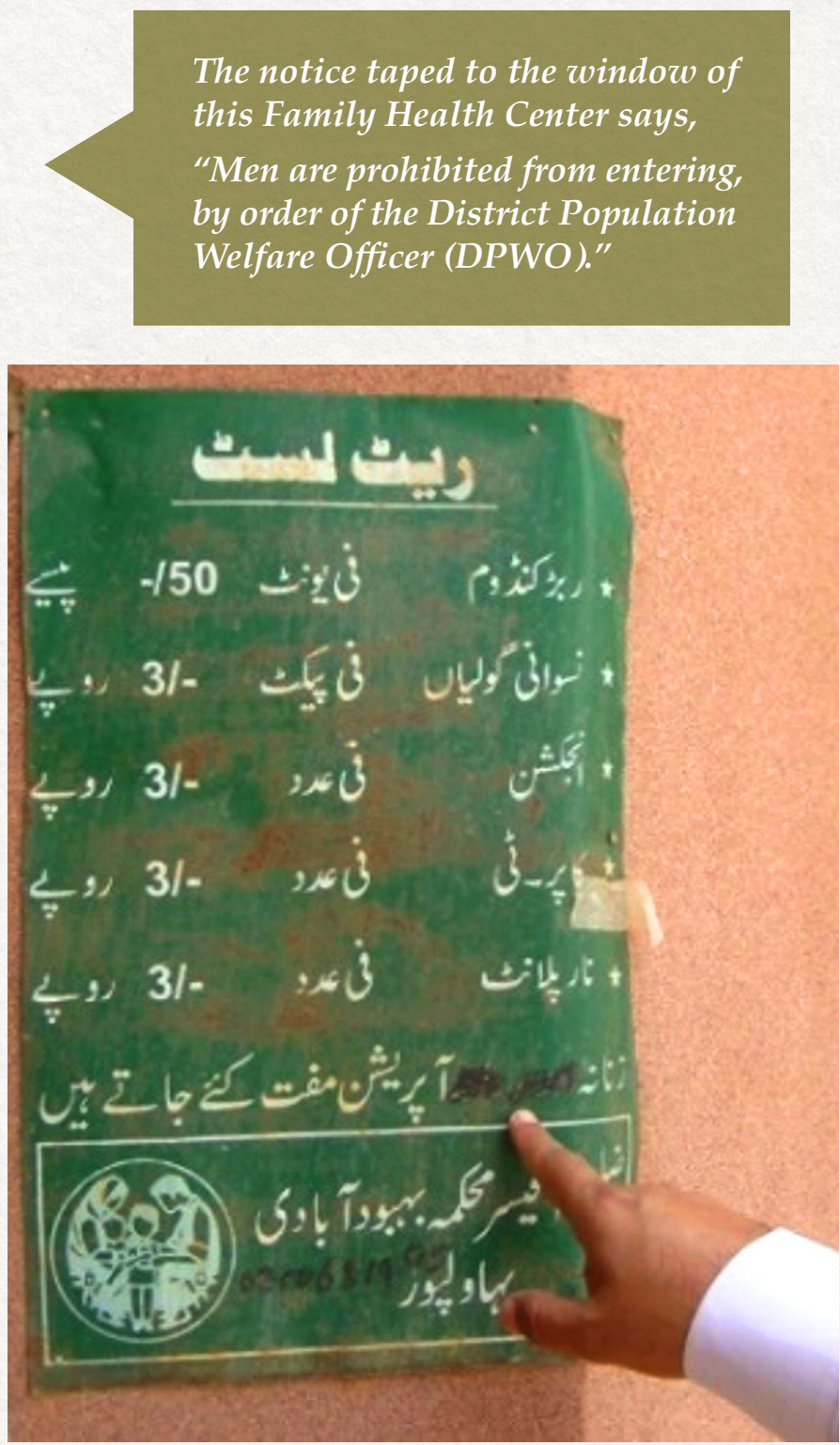
Thus, men's demands are two-fold: an improvement in the quality of services that their wives avail, especially of information exchange; and assignment of service providers for men, with whom they can interact directly and who are sufficiently skilled to provide them with complete information and referral. In particular, men need detailed information and counseling about both male and female contraceptive methods, for example, how to ensure uninterrupted use of daily pills or DMPA (depot-medroxyprogesteroneacetate) injections, and the higher risk of pregnancy associated with reversible male and traditional methods. Their concerns about side effects of female methods must be honestly addressed. They should also be apprised of the advantages of vasectomy over female sterilization, and misperceptions about the method should be dispelled.

It is also vitally important to ensure that the needs of unmarried adolescent boys and young men are not neglected. In many parts of the world, young people face greater social barriers and stigma about showing interest and engaging in sex before marriage. ${ }^{46}$ Adolescent boys and young men in Pakistan, as elsewhere, are very interested in learning about family planning methods and using them after they get married. ${ }^{47}$

\section{Recommendations}

The recommendation to include men in Family planning programs in Pakistan to accelerate progress is now part of international best practices and is included in the CCI 2018 Decisions. We basically need to move forward with mainstreaming and upscaling tested innovations for including men and boys in communications and service delivery of family planning services. There is no need to create service delivery channels as such, but we definitely need to be refocused to provide information and services to couples and men, which have focused solely on women. Proven practices should be scaled up and innovations carefully introduced to achieve this. We recommend the following strategies and actions.

\section{Make men ideational game changers}

Men's commitment to family planning can be enhanced by linking the idea of birth spacing and limiting with their own deep concern to ensure the health and wellbeing of their wives and children, and to provide for their families by achieving a balance (tawazun) between resources and consumers. These messages should be directed at men both as the usual heads of families and as religious leaders and political representatives with a leadership role.
Giving men access to family planning information and services will help increase use of family planning and enable couples to use more effective methods, particularly long-acting reversible contraceptives (LARCS). However, we want to caution that in making health services more male-friendly, it will be critically important to ensure that men's involvement does not in any way reduce women's autonomy and opportunities for them to obtain services independently. ${ }^{45}$

However, with limited avenues for information, most young boys enter adolescence without any preparation for puberty except what they learn through friends and peers and social media. Similarly, young men enter marriage ill-equipped to plan their fertility, and not surprisingly, couples typically begin childbearing soon after marriage. Use of family planning before the first birth is very low in the country ${ }^{48}$, suggesting an opportunity to counsel young men and women, before or right after marriage.
- We should ensure that advocacy and communications in support of family planning specifically also address men. In particular, the new national population narrative, which is focused on the concept of tawazun, should be utilized to dispel the perception that family planning is only for women's use; to promote couple communication on family size and family planning; and to appeal to men's desire to be caring and supportive husbands and fathers. The narrative provides a huge opportunity to give men a leadership role in normative change that stresses the rights of parents (and those considering marriage) to choose the timing and spacing of children while being fully responsible about ensuring that they have the resources to fulfill their children's rights to health and education.

- We should encourage the religious leadership to be more involved, especially in provinces or regions where Ulema (religious scholars) and maulvis (religious teachers) are important influencers of opinions and values. This is also a CCI recommendation and at the Population Summit in 2015, consensus has already been achieved across most leading ulema in the country that birth spacing is permissible and beneficial for mothers and children. 
- This can be highlighted to remove ambivalence and promote greater commitment to family planning among men (and women) as well as service providers, engaging local religious leaders for even greater impact.

\section{Sensitize and inform boys and youth}

- To address the gap in knowledge of boys transitioning to puberty, culturally acceptable and age-appropriate life skills-based education is being introduced in the country, both at school and at platforms that can serve outof-school adolescents.

- In Sindh, particularly, comprehensive sexuality education programs have been developed by the non-governmental organization (NGO) Aahung in consultation with policymakers, educators, parents, religious leaders, the health community, social scientists, and other NGOs. Such efforts should increase, using existing programming tools to jumpstart the process and ensure the work is evidence-based. Once there is consensus on the content, this curriculum should be mainstreamed in education systems and curricula.

- We could also draw on best practices used for HIV awareness raising among similar groups in Pakistan. In particular, anonymous hotlines and mHealth messages hold great potential to reach adolescent boys and young men.

- Deferring the first birth could be a key way to reduce eventual family size and build a habit of communication and use of family planning that serves couples throughout their reproductive lives. The CCI 2018 recommendations include a decision to utilize marriage (Nikah) registrars for premarital counselling, and this practice is also being tried in Iran. ${ }^{49}$ We propose testing this practice in Pakistan through linkages with the marriage registration process. In provinces and regions where there is a risk that issues of privacy and modesty (purdah) or awkwardness between young potential spouses could arise, an adaptation may be to conduct the counseling right after marriage.
- An immediate priority is to train and utilize existing male technical staff in the public health system, such as male health technicians (MHTs), to provide family planning information and services to male clients. ${ }^{50}$ Male service providers and staff will need to be trained to respond to men's questions and needs, including complete information and counseling about female methods, detailed advice on how to use male and cooperative methods, and also vasectomy services.

- Apart from technical staff and paramedics, male physicians can be trained to provide more direct information about specific contraceptive methods and also counseling about management of side effects. Discussions with representative organizations of male family physicians indicate they are eager to provide family planning services.

- With 9,000 family physicians in the private sector in Punjab alone, there is a huge, unique, and potentially important opportunity to involve men in family planning through this untapped cadre.

- Alternative medicine practitioners, such as hakeems and homeopaths, can also be encouraged to provide family planning services. These providers are well positioned and would require only modest training to counsel on contraceptive choices and dispense some basic methods during their frequent interactions with male clients.

- On the same lines, we could consider coupling our community-based Lady Health Workers with a cadre of male health workers, on the pattern of the male and female behvarz in Iran. This will ensure that both men and women are counseled, facilitating couple communication and decision-making. Male community health workers can regularly visit men, provide them with information and counseling on family planning along with contraceptives, and organize men's meetings to collectively discuss issues and conduct group counseling. ${ }^{52,53}$ Male mobilizers, called family welfare assistants, have been deployed by the Population Welfare Department for a considerable period, and recently the ad- 


\section{Support men as contraceptive users}

ditional cadre of male motivators has also been introduced. Currently employed by the governments of Punjab and Sindh, their effectiveness is limited by the large areas they are required to cover and their relatively weak linkages with the health system. Their more directed deployment is part of the $2018 \mathrm{CCI}$ recommendations and it may be important to recraft their roles.

- There is room for engaging men and boys outside of formal health facilities through creative outreach. For example, the Population Welfare program provided counseling and services to men working at selected firms for many years. Other opportunities, such as large-scale agricultural extension interventions and industrial and commercial workplace health programs, can also be tapped.

- Emerging practices like social media, hotlines, and mHealth apps, which are now game changers in reaching larger groups, should also be leveraged for widely disseminating family planning messages and information to men and boys. The potential of such interventions is enhanced by the high level of teledensity in Pakistan, and the fact that most males have direct access to mobile phones.

- Pharmacies and drug stores should be used more effectively to provide information and basic counseling to men and boys. Qualitative research suggests that pharmacists would be willing to be involved in such efforts ${ }^{54}$ and separate counseling spaces at outlets could be tested. This is a promising high-impact practice (HIP 2018) and is supported by data which show that condoms are purchased at pharmacies and drug stores by $47 \%$ of using couples in Pakistan. ${ }^{55}$ Moreover, the presence of these outlets is quite widespread, and they already serve as informal sources of health counseling for customers but are not delivering detailed information and counseling on family planning due to perceived lack of demand for commodities and lack of referral linkages.
Our final recommendation is to support men to use family planning through greater choice of methods for themselves.

- Condoms are a leading method in Pakistan, already used by a considerable proportion of couples in the country. However, men sometimes feel shy in purchasing this method from shops, while those who use public sector sources worry that the commodities are substandard or often not available with Lady Health Workers. ${ }^{56}$ Men also need advice on how to use condoms properly ${ }^{57}$, and how to pair this method with another method, such as emergency contraceptive pills, to reduce the risk of failure. These issues should be addressed by improving public sector supply chains, training providers to guide men and allay their concerns, and working with contraceptive retailers and distributors to make it easier for men to confidently purchase contraceptives. For example, exposure to a TV and radio campaign for the socially marketed condom brand Touch was associated with increased use and reduced embarrassment in purchasing condoms among men. ${ }^{58}$

- Withdrawal is also a very popular method used but this traditional method has a high risk of failure, so users must be counseled about appropriate alternative methods to reduce the risk of pregnancy. Hardee and colleagues ${ }^{59}$ note that while the method is often dismissed by the health community, it has important value as a backup method at times when couples are unable to access any other type of contraceptive. The religious permissibility of this method encouraged men in Iran to more widely practice family planning. ${ }^{60}$ Men in both urban and rural areas should be counseled about the method, and awareness about it increased.

- Standard Days Method (SDM) is a fertility awareness-based method in which couples use CycleBeads ${ }^{\circledR}$ to track fertile periods during which they abstain or use barrier methods. It 
is a reliable and affordable modern method with zero health risks that enhances couple communication and does not require resupply visits; yet it "suffers from lack of respect among family planning programmers and providers who think of it as a traditional method that is not effective, and who malign it as a 'religious' method" ${ }^{61}$ Qualitative research indicates that men in Pakistan are very interested in using SDM because it obviates issues of access and side effects ${ }^{62}$ but they, along with women, need information and counseling on how to use it effectively. Currently, only $22 \%$ of men know about this method. ${ }^{63}$ SDM should be popularized in the country through social marketing and other channels, as both a primary and backup method, harnessing mHealth solutions such as the CycleTel Humsafar tool introduced by the Georgetown University's Institute of Reproductive Health in India.
- Vasectomy is one of the least used methods in the country, in stark contrast to female sterilization, which is a more complicated procedure and has higher risks. There are many barriers to the use of vasectomy include myths about the adverse health effects of the procedure, lack of information about where to obtain services, and concerns about high costs. ${ }^{64}$ These problems could be addressed through interventions on the pattern of the ACQUIRE Project, discussed earlier.

- Emergency contraceptive pills (ECP) are an effective back up for withdrawal and other contraceptive use disruptions, but currently underutilized. Locally manufactured and available in pharmacies in urban areas, ECP could be promoted, particularly among young married couples ${ }^{65}$, who do not have access to regular contraceptive supplies due to socio-cultural inhibitions or lack knowledge about various contraceptive choices.

\section{Conclusions}

1. Involving men and boys has thus far only been regarded as an add-on feature but should be regarded as a major unique strategy to address stagnation in family planning uptakeand high fertility in Pakistan.

2. Most of the recommendations in this brief are relatively low cost and do not require new infrastructure or staff. Involving men and boys in family plann ing is thus a low-risk and high-yield investment. The strategy could be a game-changer in altering fertility intentions by changing attitudes about family responsibility and numbers of children desired as ideal, and also in opening up the health system to include men in reproductive health decisions and utilization. 


\section{References}

1. Office of Population and Reproductive Health (OPRH). 2018. Essential Considerations for Engaging Men and Boys for Improved Family Planning Outcomes. Np: OPRH, Bureau for Global Health, USAID.

2. Starrs, A. M., Ezeh, A. C., Barker, G., Basu, A., Bertrand, J. T., Blum, R., ... E Sathar, Z. A. (2018). Accelerate progress-sexual and reproductive health and rights for all: report of the Guttmacher-Lancet Commission. The Lancet, 391(10140), 2642-2692.

3. Hardee, Karen, Melanie Croce-Galis, and Jill Gay. 2016. "Men as Contraceptive Users: Programs, Outcomes, and Recommendations," Working Paper. Washington, DC: Population Council, The Evidence Project.

4. Stern, Erin. 2015. "Sexual health and rights." In Edström, J.; Hassink, A.; Shahrokh, T. and Stern, E. (eds) (2015) 'Engendering Men: A Collaborative Review of Evidence on Men and Boys in Social Change and Gender Equality', EMERGE Evidence Review, Promundo-US, Sonke Gender Justice and the Institute of Development Studies.

5. Starrs, A. M., Ezeh, A. C., Barker, G., Basu, A., Bertrand, J. T., Blum, R., ... E Sathar, Z. A. (2018). Accelerate progress-sexual and reproductive health and rights for all: report of the Guttmacher-Lancet Commission. The Lancet, 391(10140), 2642-2692.

6. Office of Population and Reproductive Health (OPRH). 2018. Essential Considerations for Engaging Men and Boys for Improved Family Planning Outcomes. Np: OPRH, Bureau for Global Health, USAID.

7. Population Reference Bureau (PRB). 2018. Engaging Boys and Men in Contraceptive Use and Family Planning: A Slide Deck. https://www.prb.org/engaging-boysand-men-in-contraception-use-and-family-planning-a-slide-deck/ ${ }^{*}$ Sufficient evidence exists about the process and impact of the proven interventions to merit their widespread implementation. Good evidence of impact also exists for the promising interventions, but it is recommended that these, along with the emerging practices, be implemented in a research context so that more can be understood about their process and impact (Hardee, Croce-Galis, and Gay 2016).

8. Hardee, Karen, Melanie Croce-Galis, and Jill Gay. 2016. "Men as Contraceptive Users: Programs, Outcomes, and Recommendations," Working Paper. Washington, DC: Population Council, The Evidence Project.

9. Stern, Erin. 2015. "Sexual health and rights." In Edström, J. Hassink, A. Shahrokh, T and Stern, E. (eds) (2015) 'Engendering Men: A Collaborative Reviezw of Evidence on Men and Boys in Social Change and Gender Equality', EMERGE Evidence Review, Promundo-US, Sonke Gender Justice and the Institute of Development Studies.

10. Barker G, Ricardo C, Nascimento M. Engaging men and boys in changing gender-based inequity in health: evidence from programme interventions. Geneva: World Health Organization; 2007.

11. Stern, Erin. 2015. "Sexual health and rights." In Edström, J.; Hassink, A.; Shahrokh, T. and Stern, E. (eds) (2015) 'Engendering Men: A Collaborative Review of Evidence on Men and Boys in Social Change and Gender Equality', EMERGE Evidence Review, Promundo-US, Sonke Gender Justice and the Institute of Development Studies

12. EngenderHealth. 2004. Mobilizing men in Nepal to support safer motherhood and reproductive health: mid-term evaluation. New York: EngenderHealth.

13. https://www.nivi.io/

14. Hardee, Karen, Melanie Croce-Galis, and Jill Gay. 2017. “Are men well served by family planning programs?" Reproductive Health 14:14. DOI 10.1186/s12978-0170278-5.

15. Population Reference Bureau (PRB). 2018. Engaging Boys and Men in Contraceptive Use and Family Planning: A Slide Deck. https://www.prb.org/engaging-boys-andmen-in-contraception-use-and-family-planning-a-slide-deck/

16. Hardee, Karen, Melanie Croce-Galis, and Jill Gay. 2017. “Are men well served by family planning programs?” Reproductive Health 14:14. DOI 10.1186/s12978-0170278-5.

17. Wilder J, Masilamani R, Daniel E. 2005. Promoting Change in the Reproductive Behavior of Youth: Pathfinder International's PRACHAR Project. Bihar, India: Pathfinder International.

18. Fahimi, Roudi. 2005. Men and Family Planning in Iran. Population Reference Bureau Maha El-Adawy, Ford Foundation. The XXVth IUSSP International Population Conference Tours, France.

19. Office of Population and Reproductive Health (OPRH). 2018. Essential Considerations for Engaging Men and Boys for Improved Family Planning Outcomes. Np: OPRH, Bureau for Global Health, USAID.

20. CARE. 2013. "The Family Planning Results Initiative in Kenya (2009 - 2012): Initial Findings from the End Line Program Evaluation." Atlanta, GA: CARE.

21. Ameen M. 2007. Reports of the International Conference of Muslim Leaders to Support Population and Development to Achieve the MDGs, Annex 19. International Conference of Muslim Leaders to Support Population and Development to Achieve the MDGs. Indonesia.

22. Nakasagga, M.F. and Nalule, S. 2016. “Village Saving and Loaning associations (VSLAs), a Platform for Increased Male Involvement for Continued Uptake of Modern Family Planning Among Marrieds." Ab $\neg$ stract at the 2016 International Conference on Family Planning. Nusa Dua, Indonesia. January 25-28.

23. Agha, S. and Meekers, D. 2010. "Impact of an advertising campaign on condom use in urban Pakistan." Stud ᄀies in Family Planning 41(4): 277-290.

24. Agha, S. and Beaudoin, C.E. 2012. "Assessing a thematic condom advertising campaign on condom use in urban Pakistan." Journal of Health Communication 17(5): 601-623.

25. Hardee, Karen, Melanie Croce-Galis, and Jill Gay. 2017. “Are men well served by family planning programs?" Reproductive Health 14:14. DOI 10.1186/s12978-0170278-5.

26. Stern, Erin. 2015. "Sexual health and rights." In Edström, J.; Hassink, A.; Shahrokh, T. and Stern, E. (eds) (2015) 'Engendering Men: A Collaborative Review of Evidence on Men and Boys in Social Change and Gender Equality', EMERGE Evidence Review, Promundo-US, Sonke Gender Justice and the Institute of Development Studies.

27. Hardee, Karen, Melanie Croce-Galis, and Jill Gay. 2017. “Are men well served by family planning programs?" Reproductive Health 14:14. DOI 10.1186/s12978-0170278-5.

28. ACQUIRE Project. 2005. "Get a Permanent Smile-Increasing Awareness of, Access to, and Utilization of Vasectomy Services in Ghana." Accessed at http://pdf.usaid. gov/pdf_docs/pdacg819.pdf.

29. Mehryar A.H., Mostafavi F., Homa A. 2001. Men and Family Planning in Iran. Tehran: Institute for Research on Planning \& Development.

30. Kothari, S. 2016. Using Social Media to promote family planning among Guatemalan men. WINGS. Unpublished.

31. Khan, A. 1996. Policy-making in Pakistan's population programme. Health Policy and Planning 11(1):30-51, https://doi.org/10.1093/heapol/11.1.30

32. Ashfaq, Seemin and Maqsood Sadiq. 2015. "Engaging the Missing Link: Evidence from FALAH for Involving Men in Family Planning in Pakistan," Case Study. Washington, DC: Population Council, The Evidence Project.

33. Mir A.M, Shaikh G.R. 2013. Islam and family planning: changing perceptions of health care providers and medical faculty in Pakistan. Glob Health Sci Pract. 1(2):228-236. http://dx.doi.org/10.9745/GHSP-D-13-00019.

34. National Institute of Population Studies (NIPS) [Pakistan] and Macro International, Inc. (1992). Pakistan Demographic and Health Survey 1990-91. Islamabad and Calverton, MD: NIPS and Macro International, Inc.

35. National Institute of Population Studies (NIPS) [Pakistan] and ICF. 2019. Pakistan Demographic and Health Survey 2017-18. Islamabad, Pakistan, and Rockville, Maryland, USA: NIPS and ICF.

36. Ibid

37. Kamran, I., Khan, M. and Tasneem, Z. 2013. Involving Men in Reproductive and Fertility Issues: Insights from Punjab. Population Council, Islamabad.

38. Population Council. 2016. Landscape Analysis of the Family Planning Situation in Pakistan. Islamabad, Population Council.

39. Kamran, Iram, Zeba Tasneem, Tahira Parveen, and Rehan Niazi. 2015. "Family Planning through the Lens of Men: Readiness, Preferences, and Challenges," Policy Paper. Washington, DC: Population Council, The Evidence Project. 
40. Rashida, Gul, Iram Kamran, Muhammad Khalil, Zeba Tasneem, Rehan M. Niazi, Mumraiz Khan, and Tahira Parveen. 2017. "Increasing access to reproductive health care through improved service delivery." Islamabad: Population Council.

41. Kamran, Iram, Zeba Tasneem, Tahira Parveen, and Rehan Niazi. 2015. "Family Planning through the Lens of Men: Readiness, Preferences, and Challenges," Policy Paper. Washington, DC: Population Council, The Evidence Project.

42. Ibid

43. Population Council. 2016. Landscape Analysis of the Family Planning Situation in Pakistan. Islamabad, Population Council.

44. Rashida, Gul, Iram Kamran, Muhammad Khalil, Zeba Tasneem, Rehan M. Niazi, Mumraiz Khan, and Tahira Parveen. 2017. "Increasing access to reproductive health care through improved service delivery." Islamabad: Population Council.

45. Stern, Erin. 2015. "Sexual health and rights." In Edström, J.; Hassink, A.; Shahrokh, T. and Stern, E. (eds) (2015) 'Engendering Men: A Collaborative Review of Evidence on Men and Boys in Social Change and Gender Equality', EMERGE Evidence Review, Promundo-US, Sonke Gender Justice and the Institute of Development Studies.

46. Population Reference Bureau (PRB). 2018. Engaging Boys and Men in Contraceptive Use and Family Planning: A Slide Deck. https://www.prb.org/engaging-boys-andmen-in-contraception-use-and-family-planning-a-slide-deck/

47. Population Council. 2016. Landscape Analysis of the Family Planning Situation in Pakistan. Islamabad, Population Council.

48. National Institute of Population Studies (NIPS) [Pakistan] and ICF. 2019. Pakistan Demographic and Health Survey 2017-18. Islamabad, Pakistan, and Rockville, Maryland, USA: NIPS and ICF.

49. Mehrolhassani, M.H., Feyzabadi, V.Y., and Rajizade, A. 2018. Evaluation of Pre-Marriage Counseling Program in Iran: A Narrative Review of Structural, Procedural, and Outcome Dimensions. Evidence Based Health Policy, Management and Economics (EBHPME) 2(2):208-25.

50. Kamran, Iram, Zeba Tasneem, Tahira Parveen, and Rehan Niazi. 2015. "Family Planning through the Lens of Men: Readiness, Preferences, and Challenges," Policy Paper. Washington, DC: Population Council, The Evidence Project.

51. Population Council. 2016. Landscape Analysis of the Family Planning Situation in Pakistan. Islamabad, Population Council.

52. Kamran, I., Khan, M. and Tasneem, Z. 2013. Involving Men in Reproductive and Fertility Issues: Insights from Punjab. Population Council, Islamabad.

53. Population Council. 2016. Landscape Analysis of the Family Planning Situation in Pakistan. Islamabad, Population Council.

54. Ibid

55. National Institute of Population Studies (NIPS) [Pakistan] and ICF. 2019. Pakistan Demographic and Health Survey 2017-18. Islamabad, Pakistan, and Rockville, Maryland, USA: NIPS and ICF.

56. Kamran, Iram, Zeba Tasneem, Tahira Parveen, and Rehan Niazi. 2015. "Family Planning through the Lens of Men: Readiness, Preferences, and Challenges," Policy Paper. Washington, DC: Population Council, The Evidence Project.

57. Hardee, Karen, Melanie Croce-Galis, and Jill Gay. 2017. “Are men well served by family planning programs?" Reproductive Health 14:14. DOI 10.1186/s12978-0170278-5.

58. Office of Population and Reproductive Health (OPRH). 2018. Essential Considerations for Engaging Men and Boys for Improved Family Planning Outcomes. Np: OPRH, Bureau for Global Health, USAID.

59. Hardee, Karen, Melanie Croce-Galis, and Jill Gay. 2017. "Are men well served by family planning programs?" Reproductive Health 14:14. DOI 10.1186/s12978-0170278-5.

60. Mehryar A.H., Mostafavi F., Homa A. 2001. Men and Family Planning in Iran. Tehran: Institute for Research on Planning \& Development.

61. Hardee, Karen, Melanie Croce-Galis, and Jill Gay. 2017. “Are men well served by family planning programs?" Reproductive Health 14:14. DOI 10.1186/s12978-0170278-5.

62. Population Council. 2016. Landscape Analysis of the Family Planning Situation in Pakistan. Islamabad, Population Council.

63. National Institute of Population Studies (NIPS) [Pakistan] and ICF. 2019. Pakistan Demographic and Health Survey 2017-18. Islamabad, Pakistan, and Rockville, Maryland, USA: NIPS and ICF.

64. Kamran, Iram, Zeba Tasneem, Tahira Parveen, and Rehan Niazi. 2015. "Family Planning through the Lens of Men: Readiness, Preferences, and Challenges," Policy Paper. Washington, DC: Population Council, The Evidence Project.

65. Population Council. 2016. Landscape Analysis of the Family Planning Situation in Pakistan. Islamabad, Population Council.

66. An exception is the recommendation to induct male $\mathrm{CHWs}$, which could be more costly in conservative settings. Potential to mainstream this intervention in the health system is discussed as part of the second Best Bet in this series. 